\title{
REPRESENTAÇÕES CULTURAIS DE SAÚDE, DOENÇA E VULNERABILIDADE SOB A ÓTICA DE MULHERES ADOLESCENTES ${ }^{a}$ Cultural representations of health, disease and vulnerability from the point of view of teenage women Representaciones culturales de salud: enfermedad y
vulnerabilidad bajo la óptica de mujeres adolescentes
}

Lucia Beatriz Ressel ${ }^{1}$

Izabel Cristina Hoffmann ${ }^{4}$
Graciela Dutra Sehnem²

Maria Celeste Landerdahl ${ }^{5}$
Carolina Frescura Junges 3

\section{RESUMO}

0 artigo apresenta um recorte de pesquisa descritiva, do tipo exploratório, com abordagem qualitativa, cujo objetivo consistiu em conhecer de que forma a cultura influencia no comportamento de adolescentes, contribuindo na sua vulnerabilidade. 0 estudo trata da visão de mulheres adolescentes que integram um projeto de ensino e extensão em desenvolvimento em escolas de ensino fundamental da Região Sanitária Norte de Santa Maria, interior do Rio Grande do Sul. Para tanto, utilizou-se como instrumento para obtenção de informações uma entrevista semiestruturada com questões que nortearam o objetivo da investigação. Os resultados apontaram para a importância da estruturação de processos educativos com adolescentes voltados para a construção de habilidades para a vida, o que permite resistir às pressões na adoção de comportamentos de risco que possam afetar sua saúde e seu desenvolvimento.

Palavras-chave: Saúde da Mulher. Adolescente. Cultura

\begin{abstract}
This article presents a descriptive research, of an explorative type, with a qualitative approach aiming at recognizing how culture influences the teenagers' behavior and, how it contributes to their vulnerability. This study discusses the view of teenager women, who are taking part in a teaching and extension project developed in junior high schools from the North Sanitary Region of the city of Santa Maria, Rio Grande do Sul State. To do so, a semi-structured interview with questions that featured the purpose of the investigation was used as instrument for obtaining the required information. The results indicated the importance of structuring educative processes with teenagers aiming at constructing abilities for life that would allow them to withstand the pressure in adopting risk behaviors that may affect their health and development.
\end{abstract}

Keywords: Women's health. Adolescent. Culture

\section{Resumen}

El presente artículo presenta un recorte de investigación descriptiva, del tipo exploratorio con abordaje cualitativo. El objetivo consistió en conocer de qué forma la cultura influencia en el comportamiento de adolescentes, contribuyendo a su vulnerabilidad. El estudio trata de la visión de mujeres adolescentes que integran un proyecto de enseñanza y extensión en desarrollo en las escuelas de enseñanza fundamental de la Región Sanitaria Norte de Santa María, interior del Río Grande del Sur. Para la obtención de las informaciones se utilizó como instrumento una entrevista semiestructurada con preguntas que orientan el objetivo de la investigación. Los resultados destacaron la importancia de la estructuración de procesos educativos con adolescentes con el objeto de formar habilidades para la vida, lo que permite resistir a las presiones para adoptar comportamientos de riesgo que puedan afectar su salud y su desarrollo.

Palabras clave: Salud de la mujer. Adolescente. Cultura

\footnotetext{
${ }^{1}$ Enfermeira. Professora Adjunto do Departamento de Enfermagem da Universidade Federal de Santa Maria (UFSM). Doutora em Enfermagem pela USP. Coordenadora do Projeto de Pesquisa. Líder do Grupo de Pesquisa Cuidado, Saúde e Enfermagem/UFSM. Tutora do Grupo PET Enfermagem. Brasil. Email: Ibressel208@yahoo.com.br, ${ }^{2}$ Enfermeira. Professora Substituta do Departamento de Enfermagem da UFSM. Mestranda do Programa de PósGraduação em Enfermagem da UFSM. Membro do Grupo de Pesquisa Cuidado, Saúde e Enfermagem/UFSM. Brasil. E-mail: graci_dutra@yahoo.com.br., ${ }^{3}$ Acadêmica do $7^{\circ}$ semestre do Curso de Enfermagem da UFSM. Membro do Grupo de Pesquisa: Cuidado, Saúde e Enfermagem. Ex-bolsista FIEX. Brasil. E-mail: cfjunges@hotmail.com., ${ }^{4}$ Enfermeira da área ambulatorial materno-infantil do Hospital Universitário de Santa Maria - RS, integrante do Núcleo de Educação Permanente em Enfermagem - NEPE; Mestranda em Enfermagem do PPGEnf da UFSM, Membro do Grupo de Pesquisa: Cuidado, Saúde e Enfermagem. Brasil. E-mail: izabel.h@gmail.com., ${ }^{5}$ Enfermeira. Professora Adjunta do Departamento de Enfermagem da UFSM. Mestre em Enfermagem pela PEN/UFSC. Membro do Grupo de Pesquisa Cuidado, Saúde e Enfermagem/UFSM. Brasil. E-mail: mclanderdahl@gmail.com.
} 


\section{INTRODUCÃO}

Contemporaneamente, 0 adolescer ganhou significativa importância, porém ainda tem sido tratado como um processo universal, limitado a uma definição conceitual relacionada mais a um aspecto biológico de vivências orgânicas do que a articulação de suas várias dimensões. Nesta direção, percebese que as mulheres adolescentes vivenciam uma construção do "ser mulher", a qual passa por um processo social e cultural específico, que se efetiva por meio da socialização de cada indivíduo.

Às mulheres essa socialização tem sido marcada pela repressão da sexualidade; pela diferenciação de condutas e de controles aplicados distintamente aos homens; pelos "nãos" que acenam aos limites constantes; pelas proibições; pela noção de inferioridade e de passividade, entre outros condicionamentos; bem como pela falta de diálogo e de esclarecimentos dos eventos biológicos, sociais e culturais que fazem parte de sua vida'.

Da mesma forma, o processo de socialização faz com que o indivíduo interiorize conhecimentos e valores que vão compor seu universo simbólico. E é nessa assimilação de conteúdos culturais que a mulher aprende a ser mulher, por meio de estratégias e recursos que induzem, naturalmente, para uma conformação abstrata, sutil, mas que amarra fortemente, deixando marcas e sinais ao longo de toda sua vida. ${ }^{1}$

Em conformidade com autora da área de Enfermagem, 2:11 compreendemos que "o viver humano é marcado pelo seu tempo e espaço, pelas possibilidades socialmente criadas pela humanidade em geral e para cada ser em particular, em face de suas também mutáveis necessidades". Assim, durante sua trajetória, a adolescente passa por mudanças e enfrentamentos sociais, os quais poderão, ou não, repercutir de forma mais ou menos intensa em sua vida, dependendo do contexto em que está inserida.

Estas transformações e enfrentamentos podem desencadear conflitos, gerando crises que se agravam com a incapacidade ou despreparo da jovem e/ou de sua família para enfrentar e conviver com o advento do adolescer.

A adolescência é determinada pela Organização Mundial de Saúde (OMS) numa faixa etária que vai dos 10 aos 19 anos e, pelo Estatuto da Criança e do Adolescente (ECA), dos 12 aos 18 anos, porém esta demarcação por faixa etária não abarca o entendimento da adolescência como um processo social. Ressaltamos que é preciso considerar as condições econômicas, políticas, sociais e culturais que determinam comportamentos individuais e grupais dos adolescentes ${ }^{2}$.

Entendemos, neste viés, a adolescência como um fenômeno único e diverso, pois as necessidades das adolescentes dependem de seu meio social, cultural, econômico e psicológico.
Assim, tratamos este evento circunscrito cultural e historicamente.

Nesta linha de pensamento, nossa atenção às mulheres adolescentes justifica-se pela compreensão de que o processo de adolescer é caracterizado por modificações biopsicossociais significativas, o que torna as adolescentes vulneráveis ao seu meio social e cultural, podendo representar um risco, à medida que as expõe aos indicadores de morbimortalidade.

Com intuito de contribuir nas demandas de tal realidade, implementamos um Projeto de Ensino e Extensão denominado "Adolescer: crescer e viver", o qual tornou oportunos espaços dialógicos e reflexivos à contemplação da construção da mulher como sujeito de ação no mundo, pois, nesta fase da vida, são criados, reforçados e reproduzidos valores culturais estendidos na sua existência. Esta atividade foi realizada em escolas de ensino fundamental da Região Sanitária Norte do município de Santa Maria no Rio Grande do Sul; região em que o Curso de Enfermagem da Universidade Federal de Santa Maria desenvolve, desde 1993, um Projeto-mãe, com ações de promoção da saúde com crianças, adolescentes e adultos, tendo referência uma Unidade Sanitária do município.

Como forma de ampliar o conhecimento obtido mediante ações já desenvolvidas com as adolescentes do projeto mencionado, foi realizada a pesquisa "A influência cultural na vulnerabilidade das adolescentes participantes do projeto Adolescer, Crescer e Viver", a qual originou o presente artigo. Neste recorte, procuramos elucidar as significações, conceituações e representações culturais de saúde, doença e de vulnerabilidade sob a ótica de mulheres adolescentes.

A doença, entendida como fenômeno eminentemente social, estabelece uma relação entre a ordem biológica e a ordem social, pois ao mesmo tempo em que atinge as funções biológicas do indivíduo, atinge também a sociedade, um determinado conjunto de relações sociais. Sendo assim, as conceituações que as diversas sociedades e classes sociais conferem para a doença não se limitam meramente a sua causa, remetendo, porém, à busca de um sentido mais amplo, que explique não apenas o mal biológico, mas as circunstâncias deste, ou seja, seu contexto social de produção. ${ }^{3}$

Alicerçando-se nessas premissas, entende-se que a compreensão de saúde e doença deve estar associada às significações culturais de cada ser humano, as quais podem ser modificadas ou adaptadas conforme o meio em que está inserido. ${ }^{4}$

0 adolescente encontra-se vulnerável e exposto a muitos riscos, pelas transformações pelas quais ele passa entre a infância e a condição de adulto, pois ele vislumbra a possibilidade de poder e autocontrole sobre sua vida. É comum nesta fase o afastamento da família e a identificação a grupos de sua semelhança; essa reorganização social muitas vezes preocupa pais, educadores e profissionais da saúde, pelo receio da aproximação com grupos usuários de drogas, na busca pelo novo ou diferente. ${ }^{5}$ 
Quanto à vulnerabilidade, suas estratégias de redução têm procurado ampliar as ações do plano individual para o plano das suscetibilidades socialmente configuradas. Dessa forma, há de se assumir responsabilidades que vão além da tarefa de alertar sobre o problema. Necessita-se, para tanto, que os sujeitos sociais respondam de forma a superar os obstáculos materiais, culturais e políticos que os mantém vulneráveis. Além do uso da informação, é preciso que as pessoas saibam como lançar mão de mecanismos de proteção e de mobilização para que as situações que as tornam suscetíveis ao adoecimento sejam de fato transformadas. ${ }^{6}$

A partir disso, emerge a compreensão de que o enfoque educacional, fundamental nos processos de promoção da saúde e prevenção de agravo, não pode ficar preso às tendências modeladoras, extremamente difundidas a partir do paradigma comportamentalista. Ao contrário dessas tendências, ao se assumir uma postura construtivista, busca-se o despertar para o fato de as pessoas buscarem e apropriarem-se de informações que façam realmente sentido às suas vidas, mobilizando-se autenticamente para alternativas práticas que permitam a superação das situações que as vulnerabilizam. ${ }^{6}$

Diante do exposto, percebe-se a necessidade de um caminhar paralelo entre a educação e a saúde, as quais se caracterizam pela sua interdependência, o que denota a essência do desenvolvimento de ações construídas com os adolescentes, na perspectiva de estes tornarem-se agentes multiplicadores de saúde.

\section{METODOLOGIA E ESTRATÉGIA DE AÇÃO}

0 estudo delineou-se como uma pesquisa descritiva, do tipo exploratório, com abordagem qualitativa, cujo objetivo consistiu em conhecer como a cultura influencia 0 comportamento das adolescentes, contribuindo na sua vulnerabilidade.

Os sujeitos da pesquisa foram 18 adolescentes de duas escolas estaduais de ensino fundamental, participantes do Projeto de Ensino e Extensão "Adolescer: crescer e viver", do Curso de Enfermagem da Universidade Federal de Santa Maria (UFSM). Os critérios de seleção para composição da amostra constituíram-se em: ser mulher adolescente; participante deste projeto; e aceitar livremente, e com concordância dos pais ou responsáveis em participar da pesquisa.

A coleta dos dados foi realizada por meio de entrevistas semiestruturadas, aplicadas individualmente mediante agendamento prévio nas escolas em que as adolescentes estudam. As questões formuladas foram estimuladoras para as participantes falarem sobre sua compreensão sobre adolescência; saúde; doença; fatores de risco na adolescência, bem como sobre as condições de exposição a eles; hábitos de saúde; sexualidade e relacionamento familiar. Neste recorte, apresentamos as concepções das mulheres adolescentes sobre saúde, doença e vulnerabilidade.
As questões éticas seguiram as orientações da Resolução $n^{0}$ 196/96 do Ministério da Saúde ${ }^{7}$ e contemplaram a informação clara e acessível acerca do projeto às adolescentes, seus pais ou responsáveis e direção das escolas envolvidas, incluindo, no termo de aceite de participação na pesquisa, os aspectos referentes à guarda e responsabilidade do material gravado e uso adequado deste para publicação em periódicos e eventos da área da saúde, bem como 0 anonimato das participantes. A pesquisa foi aprovada no Comitê de Ética da Universidade Federal de Santa Maria, sob o protocolo $n^{0} 047 /$ 05, em 25 de julho de 2005.

A análise dos dados seguiu a orientação de estudo das Ciências Sociais ${ }^{8}$ que inclui a ordenação e categorização dos dados a partir de um processo de leitura de todo o conteúdo com registro consecutivo dos temas recorrentes; e a interpretação dos dados, a partir das aproximações com o referencial teórico do estudo.

\section{APRESENTAÇÃO DOS DADOS E DISCUSSÃO}

As participantes da pesquisa caracterizaram-se por serem de etnia branca (47\%), mulata (31\%), negra (10\%) e parda $(8 \%)$. A religião predominante foi a católica $(51 \%)$, seguida de religião não definida (36\%) e evangélica (12\%). Acusaram morarem com seus pais e irmãos ( $57 \%$ ), e com outras pessoas (43\%). Quanto à ocupação, foram relatadas atividades de estudo e auxílio em tarefas domésticas (95\%), bem como realização de serviços com fins econômicos, como cuidar de crianças (5\%).

\section{Concepções acerca de saúde, doença $E$ vulnerabilidade}

Embora exista um forte componente biológico que lhe é próprio, o processo de adolescer não é simplesmente uma consequência exclusiva do ciclo evolutivo, o que confere ao adolescente necessidades que precisam ser satisfeitas. Os processos de construção/reconstrução e apropriação ou não de bens e valores materiais, e a interação destes com os processos somáticos, genéticos e físico-ambientais é que definem os diversos modos de vida das adolescentes. ${ }^{2}$

Ao refletir sobre a adolescência na perspectiva biomédica, percebe-se a emersão de aspectos que a limitam e a enquadram em parâmetros biologicistas, tanto nas transformações da puberdade quanto no desenvolvimento psicossocial. A partir desta questão, suscitamos a discussão sobre os significados de saúde, de doença e de vulnerabilidade com as adolescentes, estimulando-as a refletirem sobre a construção cultural de suas vivências.

Assim, quando questionadas a respeito de como cuidavam de sua saúde, as adolescentes abordaram em seus discursos situaç̃̃es e cuidados consigo mesmas associadas à promoção da saúde. 
É cuidar do corpo, se prevenir de algumas coisas? A1

\section{Fazer esportes físicos. A6}

\section{Faço academia com minha mãe. A7}

Me alimentar bem, dormir bem... A8

Ao referirem cuidados com a alimentação, sono e atividades físicas, entre outras, as adolescentes expressam, ao mesmo tempo, sua compreensão sobre saúde imbricada na noção de qualidade de vida. Isso ficou mais claro quando as adolescentes foram questionadas sobre sua concepção de saúde, cabendo destacar suas falas.

Pra mim, ter saúde é ter boa disposição, levantar com bom humor, praticar exercícios, limpar a casa, escutar música, conversar com os amigos, vir para o colégio. A4

Ter saúde é ser feliz. A10

Percebe-se que o conceito mencionado pelas adolescentes, embora bastante ligado ao bem-estar físico, supera a visão de saúde como mera ausência de doença, sendo possível perceber elementos descritos no conceito de saúde da VIII Conferência Nacional de Saúde 9:10, o qual apregoa que "saúde é o resultante das condições de alimentação, habitação, educação, renda, meio ambiente, trabalho, transporte, lazer, liberdade, acesso e posse da terra e acesso aos serviços de saúde". A constatação de que uma nova geração parece já estar absorvendo princípios e valores da Reforma Sanitária Brasileira é muito promissor, uma vez que o sistema público de saúde em vigência no Brasil já tem 20 anos, sendo imperioso que uma nova cultura se estabeleça nessa área.

Ao tangenciarmos a discussão sobre doença, observamos que as adolescentes reforçaram essa percepção mencionada, apresentando um saber consoante com uma nova cultura em saúde; cultura essa associada, também, à subjetividade do viver humano. Com isso, as respondentes avançaram quando da questão anterior, uma vez que não se ativeram unicamente ao caráter biológico da doença. Isso é possível perceber nas falas das envolvidas no estudo.

\section{É estar triste. A3 \\ É não se cuidar. A7}

Uma coisa assim que te deixa desanimado, que incomoda bastante, deixa a gente pra baixo, a gente não quer saber de ninguém, quer ficar isolada num canto, pra mim isso é ter doença. Também tem várias outras coisas que são as desavenças entre pai e mãe e com os irmãos. A13

Em conformidade com autora da área de Ciências Sociais ${ }^{8}$, as concepções de doença são explicadas por elas como resultados de fatores naturais e psicossociais. Essas concepções resultam de modos de viver individualizados, porém se congregam ao considerarem a complexidade dinâmica dos aspectos biopsicossocias do ser humano. Há que lembrar, no entanto, que a compreensão ampliada das adolescentes é resultado de uma caminhada cultural de duas décadas no campo da saúde no Brasil; bem como de um investimento no aspecto educativo realizado no contexto de discussões geradas no próprio projeto de extensão, que deu origem à presente investigação, desenvolvido com elas.

Ao serem questionadas quanto aos riscos à saúde na adolescência, as entrevistadas associaram a vulnerabilidade dessa fase ao uso indevido de drogas e à prática de sexo inseguro, como percebemos a seguir:

\section{Se não usar camisinha, engravida. A5}

Risco de saúde é usar drogas. A9

Tem que se cuidar, usar camisinha. A18

Risco pro adolescente? É fumar, beber. A11

Entendemos que a vulnerabilidade da adolescente decorre da multiplicidade de fenômenos que ocorrem nessa etapa do ciclo evolutivo. A partir dessa fase, ela passa a ter maior conhecimento de si mesma e por isso pode estar mais sensível e suscetível às situações de seu cotidiano. Somam-se a isso os contextos cultural, social e econômico que moldam a vida da adolescente.

Ao ser abordada a questão de gênero como um aspecto associado a riscos no processo de adolescer, as entrevistadas apontaram as meninas como mais sujeitas a exposição a riscos, conforme discorrido nas falas abaixo:

As meninas ultimamente andam muito assanhadas. A15

\section{A mulher é mais sensível. A14}

Porque as meninas têm a preocupação em satisfazer os meninos, as meninas são muito novas e aí acabam engravidando, daí o risco é o parto, eu mesma já engravidei. A7

As duas primeiras falas reproduzem exatamente o que a sociedade pensa em relação à mulher: umas são "assanhadas" e todas são "mais sensíveis". Tal compreensão, em especial a primeira, denota certo preconceito em relação à mulher que toma determinadas iniciativas no campo das relações afetivas, evidenciando o que é permitido aos homens e o que é permitido às mulheres. Já a segunda fala integra um conjunto de características ditas "naturais", as quais, no entanto, foram construídas culturalmente por meio de regras e condicionamentos que valorizam e permitem à menina a expressão da sensibilidade e a negam ao menino.

A terceira adolescente, todavia, avança em seu olhar, demonstrando uma visão muito madura da realidade. Sua fala destoa das demais na medida em que consegue perceber a 
forma peculiar como as meninas tentam agradar os meninos para não perdê-los. Sua visão vai mais longe quando acusa que tal postura representa riscos, pois pode levar a uma gravidez indesejada, que a obriga, muitas vezes, a tomar decisões sem o apoio do menino. Depoimentos como os dessa respondente sem dúvida podem contribuir para o respeito da sociedade em relação à mulher.

Cabe ressaltar que um menor número de adolescentes respondeu que os meninos estão mais expostos a situações de risco durante esse processo, conforme os relatos:

Os meninos são metidos a machão. A3

Eu acho que os meninos se cuidam menos. A6

A maioria dos guris gosta de andar solto assim, de andar com seu grupinho e sempre tem um que usa cigarro, que fuma, que usa maconha, álcool, essas coisas. A17

Igualmente nessas falas está imbricada toda a construção cultural contida na identidade masculina em contraposição à feminina.

Neste sentido, as relações distintas de gêneros são adotadas em vários âmbitos, coletivas e individuais, decretando obstáculos sociais. Esta questão é percebida pela sociedade de maneira natural, emergindo das atividades e funções das mulheres e dos homens. Sendo assim, parece que tais papéis são imutáveis, mantendo as desigualdades de gênero. ${ }^{10}$

Ainda, algumas adolescentes responderam que tanto meninas quanto meninos estão igualmente expostos a riscos na adolescência, o que pode ser observado a seguir:

Ambos, eu acho. Porque hoje em dia, por exemplo, se tu sair sem proteção qualquer um pode pegar doenças, AIDS... A11

Essa fala permite compreender que as adolescentes percebem que a vulnerabilidade existe tanto para meninos como para meninas, a depender do grau de exposição aos riscos que se apresentarem. Acreditamos que esse entendimento se dá à custa das informações disponibilizadas com relação às doenças que 0 adolescente pode "pegar", principalmente a AIDS.

Depende, acho que isso não é só de menino ou menina, depende de quem amadurece mais cedo. A14

Já, essa fala denota que o amadurecimento pode ser um elemento importante na tomada de decisões tidas como adequadas e preventivas de riscos para a saúde dos adolescentes.

Entende-se que as preocupações referentes ao crescimento do corpo, à sexualidade, à compreensão da família, ou mesmo aos conflitos familiares, a busca de uma identidade, a insegurança quanto à aceitação pela turma, a luta por mais autonomia (antidependência) e a onipotência juvenil possivelmente caracterizem o processo de adolescer e possam ao mesmo tempo ser os causadores de agravos de saúde para o adolescente. Por isso, a adolescência é percebida como uma fase delicada, talvez a mais vulnerável etapa de todo 0 desenvolvimento humano. ${ }^{11}$

\section{CONSIDERAÇÕES FINAIS}

A adolescência é um período de transformações físicas, psicológicas e culturais, trazendo aos jovens dúvidas e questionamentos que muitas vezes os deixam confusos. Todo o desenvolvimento corporal aliado ao afloramento da sexualidade feminina e masculina faz com que esta seja uma fase da vida que mereça atenção especial, pois é nessa época que o adolescente questiona, descobre e afirma sua personalidade perante a sociedade. A transição da infância para a vida adulta é para os adolescentes uma fase de descobertas, de novas experiências.

Nessa perspectiva, entende-se a importância da efetivação de processos educativos com adolescentes, voltados para a construção de habilidades para a vida, o que permite resistir às pressões para adoção de comportamentos de risco que possam agredir sua saúde e seu desenvolvimento. Dessa maneira, será possível estimular o protagonismo juvenil no enfrentamento da vulnerabilidade desta faixa etária aos riscos que estão expostos os adolescentes.

Ressaltamos que a educação em saúde junto ao adolescente, analisada sob a ótica da educação popular, tende a valorizar os seus saberes na construção de uma proposta de atenção básica e também terapêutica centrada no sujeito do cuidado. ${ }^{12} 0$ elo entre metodologias de pesquisa participativas e a educação popular em saúde tem sido debatida como uma estratégia vantajosa no campo da atenção básica porque promove o diálogo intersubjetivo e a interação entre sujeitos e pesquisadores. ${ }^{13}$

Cientes deste processo, acreditamos que o estudo desenvolvido foi propulsor de ponderação crítica quanto à orientação de ações às mulheres adolescentes, gerando um espaço de sensibilização e conscientização e possibilitando o despertamento para uma ressignificação de emoções, valores e conhecimentos a todas as participantes .

0 exercício deste estudo possibilitou às acadêmicas de Enfermagem um preparo para coleta de dados, um balizamento acerca da temática e a vivência de atividades grupais com adolescentes, pois no segundo momento da pesquisa, após a coleta dos dados, realizaram-se oficinas lúdicas com as adolescentes, permitindo a criação de um espaço reflexivo envolvendo os temas de interesse delas.

Diante do exposto, consideramos que os profissionais da saúde devem procurar conhecer, em uma perspectiva cultural, as mulheres adolescentes, ou seja, como estas vivenciam seu processo de amadurecimento e de vivência do adolescer, pois 
somente dessa maneira poderão ser planejadas ações de cuidado, prevenção e promoção à saúde de forma integral.

Conclui-se que as práticas de saúde com mulheres adolescentes devem envolver o compartilhamento de experiências, criando oportunidades de espaços para o diálogo e a reflexão das vivências pelas próprias jovens.

\section{REFERÊNCIAS}

1. Ressel LB. Vivenciando a sexualidade na assistência de enfermagem: um estudo na perspectiva cultural [tese de doutorado]. São Paulo (SP): Escola de Enfermagem/ USP; 2003.

2. Ramos FRS, Pereira SM, Rocha CRM. Viver e adolescer com qualidade. In: Ramos FRS, organizadora. Adolescer: compreender, atuar, acolher. Brasília (DF): ABEn; 2001. p.11-8.

3. Knauth DR. Corpo, saúde e doença. Cad Antropol, Porto Alegre 1992; 5:55-72.

4. Benetti SRD, Lenardt MH. Significado atribuído ao sangue pelos doadores e receptores. Texto Contexto Enferm 2006 jan/mar; 15(1): 43-50.

5. Filho AJA, Ferreira MG, Gomes MLB, Silva RC, Santos TCF. 0 adolescente e as drogas: conseqüências para a saúde. Esc Anna Nery Rev Enferm 2007 dez; 11(4): 605-10.
Ressel LB, Sehnem GD, Junges CF, Hoffmann IC, Landerdahl MC

6. Ayres JRCM, França Júnior I, Calazans JG, Salete Filho HC. 0 conceito de vulnerabilidade e as práticas de saúde: novas perspectivas e desafios. In: Czeresnia D, Freitas CM, organizadores. Promoção da saúde: conceitos, reflexões, tendências. Rio de Janeiro (RJ): Fiocruz; 2003.

7. Ministério da Saúde (BR). Conselho Nacional de Saúde. Resolução n 196 de 10 outubro de 1996. Diretrizes e normas regulamentadoras de pesquisa envolvendo seres humanos. Brasília (DF); 1996.

8. Minayo MCS. 0 desafio do conhecimento: pesquisa qualitativa em saúde. 8.ed. São Paulo (SP): Hucitec; 2004.

9. Minayo MCS. A saúde em estado de choque. Rio de Janeiro (RJ): Espaço e Tempo; 1992.

10. Torres CA, Beserra EP, Barroso MGT. Relações de gênero e vulnerabilidade às doenças sexualmente transmissíveis: percepções sobre a sexualidade dos adolescentes. Esc Anna Nery Rev Enferm 2007 jun; 11(2):296-302.

11. Tiba I. Sexo e adolescência: desenvolvimento psicossocial. São Paulo (SP): Ática; 1996.

12. Albuquerque PC, Stotz EM. A educação popular na atenção básica à saúde do município: em busca da integralidade. Interface: comunicão, saúde, educação 2004 mar/ago; 8(15): 259-74.

13. Tavares SMG. Pesquisa participante: possibilidades e repercussões na área de educação em saúde. Bol Inst Saude 2004 dez; (34): 15.

\section{Nota}

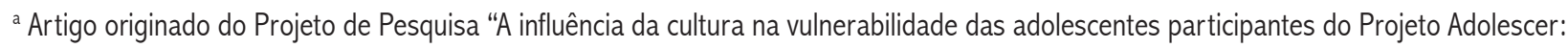
crescer e viver". Financiado com bolsa de Iniciação Científica PIBIC/CNPq. 